\title{
A Basic Study on the Spatial Hierarchy Correlation between Apartment Complexes and Senior Citizen Centers
}

\author{
Xiaolong Zhao ${ }^{1}$, Heangwoo Lee ${ }^{2 *}$ \\ ${ }^{1}$ Graduate Student, Major of Interior Design, Department of Design, \\ Sangmyung University, Cheonan, Korea \\ ${ }^{2 *}$ Assistant Professor, Major of Space Design, College of Design, \\ Sangmyung University, Cheonan, Korea \\ 1whgyfyd@naver.com, 2*2hw@smu.ac.kr
}

\begin{abstract}
The need for research on elderly facilities outside of apartment complexes is growing because the senior citizen centers located inside apartment complexes are not enough to accommodate the rapidly increasing elderly population. However, most of the previous studies on senior citizen centers focused on the inner space design of these facilities, so they do not provide the basic data required to design senior citizen centers in the future. Also, the use of elderly community centers in large apartment complexes was reduced, which may be due to accessibility. Therefore, this study analyzed the accessibility and recognizability of senior citizen centers by analyzing the spatial hierarchy correlation between apartment complexes and senior citizen centers located outside these complexes. This study selected senior citizen centers near apartment complexes in a populated area and performed the research in four stages according to the following procedure to establish a spatial hierarchy correlation between brand apartment complexes and senior citizen centers located outside these complexes by applying space syntax methodology. First, the concept of senior citizen centers and space syntax was considered. Then, a total of four apartment complexes in Songpa-gu, Korea, and two senior citizen centers adjacent to each complex were selected for the analysis. The results are as follows. The senior citizen centers near the apartment complexes showed above average results in most of the indicators compared to the survey area. This means that the accessibility and recognizability of the senior citizen centers outside the apartment complexes were good. However, the index related to accessibility and recognizability inside the apartment complexes was relatively low, so senior citizen centers inside apartment complexes should be planned by considering the factors related to senior citizen centers outside these complexes in the future.
\end{abstract}

Keywords: Senior citizen center, Brand apartment, Space syntax, Accessibility

\section{Introduction}

Aging is emerging as a serious global issue [1][2][3]. Aging population is rapidly progressing not only in Korea but also in other countries around the world [4], and social preparations and related research are required to re-solve this trend. Accordingly, the importance of social facilities for the elderly is increasing as the number of elderly facilities gradually increases. Among these facilities for the elderly, senior citizen centers or elderly community centers are

Article history:

Received (December14, 2020), Review Result (January 19, 2021), Accepted (January 4, 2021) 
social welfare facilities where the elderly can gather and make use of their leisure time, and the number of such facilities is increasing gradually [5]. In Korea, the number of apartment complexes has increased, and various facilities are being distributed around these complexes. In general, senior citizen centers are required to be installed in apartment complexes, raising the need for research to improve the quality of senior citizen centers in apartment complexes. However, most of the senior citizen centers currently installed in apartment complexes are not suitable for accommodating the elderly living in these complexes as they are built according to the minimum scale required by law. Therefore, the demand for senior citizen centers adjacent to apartment complexes is increasing as well as the importance of relevant research on such facilities. However, most recent studies on senior citizen centers have focused on the facilities and composition of indoor spaces, so there is a lack of research on the accessibility and recognizability of senior citizen centers. Therefore, the purpose of this study is to build basic data for the design of senior citizen centers in the future by selecting an area where apartment complexes are concentrated and analyzing the spatial hierarchy of apartment complexes and senior citizen centers located outside these complexes.

\section{Senior citizen center and analysis method consideration}

\subsection{The concept and installation standards for senior citizen centers}

A senior citizen center is a type of social welfare facility where the elderly can gather and make use of their leisure time, a place where senior citizens in the neighborhood gather to talk, acquire knowledge, maintain healthy hobbies, and participate in pastime activities [6]. While senior citizen centers are basically available to the elderly aged 65 or older, there are also senior citizen centers by age groups due to the recent improvements in quality of life and the development of medical technologies. According to the regulations on housing construction standards enacted by the Ministry of Land, Infrastructure and Transport in 2017 [7], housing complexes with more than 100 households must install resident community facilities that are larger than the area calculated according to the regulations, and housing complexes with more than 150 households must have senior citizen centers.

\subsection{Consideration of spatial hierarchy analysis methodology}

This study used space syntax to analyze the spatial hierarchy correlation between apartment complexes and senior citizen centers. Space syntax was developed by Bill Hillier and Julienne Hanson as a set of techniques to investigate spatial layouts and hierarchy by analyzing configurative spatial relationships [8]. Space syntax analysis uses convex spaces and axial maps depending on the analysis method and subject, and this study used axial maps to analyze the circulation hierarchy around apartment complexes. In space syntax, indices related to recognition such as connectivity, global integration, and local integration are derived based on the hierarchy and connection of axial lines. Connectivity measures the number of axial lines connected to a certain axial line, so low connectivity means that it is not a major circulation or traffic line. Global integration means that it is easier to move to other spaces in the entire area, making it more accessible. On the other hand, local integration is calculated by considering the spatial depths from each space, indicating the relative recognizability of each space.

\section{Analysis subject and results}

\subsection{Analysis method}


This study analyzed the spatial hierarchy of residential complexes and senior citizen centers, and for this purpose, the residential complexes were limited to apartment complexes. In Korea, apartments are typical common residential complexes accounting for $59.9 \%$ of all of the houses [9]. This is the reason why this study limited the scope of analysis to apartments. First, this study limited the range to Seoul, Korea, to choose the subject for analysis. Then, based on the Population and Housing Census by the National Statistical Office in 2019, Songpa-gu, which has the largest population in Seoul, was selected as the scope for choosing the subject for analysis. Finally, to achieve the purpose of this study, apartment complexes with the appropriate facilities in terms of size and characteristics were selected. The process is shown in Figure 1.

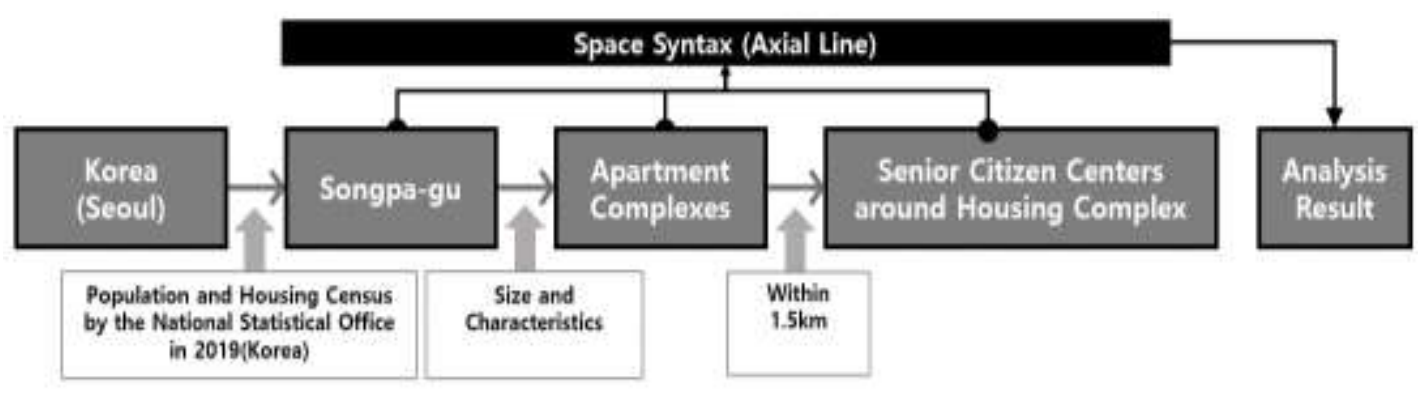

Figure 1. Research procedure

\subsection{General status of survey area}

The [Table 1] shows the four apartment complexes selected by this process. To analyze the circulation hierarchy between the selected apartment complexes and senior citizen centers, the senior citizen centers were limited to facilities located outside the complexes and within $1.5 \mathrm{~km}$ in consideration of the mobility of senior citizens. [Table 2] shows the eight senior citizen centers that meet these conditions, and all of these centers opened before 2000.

Table 1. Housing complex overview

\begin{tabular}{|c|c|c|c|c|}
\hline Apartment complex & Large area of land & Building area & Occupancy date & Senior citizen center \\
\hline Jamsil LLL's & $231,604.70 \mathrm{~m}^{2}$ & $34,370.96 \mathrm{~m}^{2}$ & Sept 2008 & 1 \\
\hline Jamsil Ricenz & $219,217.90 \mathrm{~m}^{2}$ & $33,257.95 \mathrm{~m}^{2}$ & Jul 2008 & 1 \\
\hline Jamsil III-zium & $150,784.80 \mathrm{~m}^{2}$ & $19,653.56 \mathrm{~m}^{2}$ & Aug 2007 & 1 \\
\hline Jamsil Lake Palace & $126,628.30 \mathrm{~m}^{2}$ & $17,841.76 \mathrm{~m}^{2}$ & Dec 2006 & 1 \\
\hline
\end{tabular}

Based on the above, this study derived axial maps to analyze the accessibility and recognizability of senior citizen centers located outside Jamsil-dong, where apartment complexes are concentrated, and Samjeon-dong and Seokchon-dong, in an extension of user circulations. By referring to the traffic lines displayed on Naver Map, this study derived the results by comparing the mean values of the connectivity, global integration, and local integration of the apartment complexes, the entire survey area (Jamsil-dong, Samjeon-dong, Seokchon-dong), and the senior citizen centers located outside the apartment complexes through the derived axial maps. 
Table 2. Overview of senior citizen centers (SCC) around housing complex

\begin{tabular}{|c|c|c|c||c|c|c|c|}
\hline \multicolumn{2}{|c|}{ Apartment Complex } & $\begin{array}{c}\text { Building } \\
\text { Area }\end{array}$ & $\begin{array}{c}\text { Opening } \\
\text { Day }\end{array}$ & \multicolumn{2}{|c|}{ Apartment Complex } & $\begin{array}{c}\text { Building } \\
\text { Area }\end{array}$ & $\begin{array}{c}\text { Opening } \\
\text { Day }\end{array}$ \\
\hline Shincheon SCC & (A) & $159.9 \mathrm{~m}^{2}$ & 1985.09 & Samjeon SCC No. 1 & (E) & $187.3 \mathrm{~m}^{2}$ & 1986.10 \\
\hline Samjeon SCC & (B) & $103.3 \mathrm{~m}^{2}$ & 1988.12 & Obongsan SCC & (F) & $106.8 \mathrm{~m}^{2}$ & 1990.08 \\
\hline Sinjamsil SCC & (C) & $106.8 \mathrm{~m}^{2}$ & 1990.08 & Seokchon SCC & (G) & $157.0 \mathrm{~m}^{2}$ & 1997.11 \\
\hline Samjeon SCC No. 2 & (D) & $49.2 \mathrm{~m}^{2}$ & 1987.11 & Dolmari SCC & (H) & $155.7 \mathrm{~m}^{2}$ & 1987.12 \\
\hline
\end{tabular}

\subsection{Analysis results and discussion}

This study investigated the spatial structure of the areas where apartment complexes are concentrated in Songpa-gu, Seoul, and the user circulations near these areas, to analyze the accessibility and recognizability of apartment complexes and senior citizen centers located outside of these complexes. The results are as follows.

First, Jamsil-dong, Samjeon-dong, and Seokchon-dong, located in Songpa-gu, consist of a total of 2016 axial lines, of which the four apartment complexes mentioned above consist of $249,339,170$, and 99 axial lines, respectively. Table 3 shows analysis results and the axial map for connectivity. As a result of analyzing the connectivity, the maximum, minimum, and mean connectivity of the survey area were 33,1 , and 3.508 , respectively. The maximum, minimum, and mean connectivity inside the apartment complexes were 17,1 , and 3.327 , respectively. In terms of comparing the connectivity of the survey area and inside the apartment complexes, the mean value of the survey area was higher than the mean value inside the apartment complexes, indicating that the utilization rate would be low inside these complexes in terms of spatial hierarchy. The connectivity of the axial lines that directly expose the locations of outside senior citizen centers A, B, C, D, E, F, G, and H, were 4.000, 2.000, 5.000, 19.500, 6.000, 4.000, 13.500, and 4.000, respectively. The connectivity of Senior Citizen Center B was lower than the mean value of the survey area and the apartment complexes, while all of the others were above the mean value. This means that the other outside senior citizen centers except for Senior Citizen Center B are located in relatively high-use areas.

Table 3. Analysis of connectivity map of the apartment complex

\begin{tabular}{|c|c|c|c|c|c|}
\hline \multicolumn{2}{|c|}{ Analysis Target } & Max & Min & Average & Connectivity Analysis Result Image \\
\hline \multicolumn{2}{|c|}{ Apartment complex } & 17 & 1 & 3.327 & \\
\hline \multicolumn{2}{|c|}{$\begin{array}{l}\text { Jamsil-dong + Samjeon- } \\
\text { dong + Seokchon-dong }\end{array}$} & 33 & 1 & 3.508 & \\
\hline \multirow{8}{*}{$\begin{array}{l}\text { Outside senior } \\
\text { citizen center }\end{array}$} & $\mathrm{A}$ & & \multirow{8}{*}{ - } & 4.000 & \\
\hline & B & & & 2.000 & \\
\hline & $\mathrm{C}$ & & & 5.000 & \\
\hline & $\mathrm{D}$ & & & 19.500 & \\
\hline & E & & & 6.000 & \\
\hline & $\mathrm{F}$ & & & 4.000 & \\
\hline & $\mathrm{G}$ & & & 13.500 & \\
\hline & $\mathrm{H}$ & & & 4.000 & \\
\hline
\end{tabular}


Second, as shown in [Table 4], the maximum, minimum, and mean global integration of the survey area were $1.799,0.309$, and 1.015 , respectively. The maximum, minimum, and mean global integration within the apartment complexes were 1.784, 0.506, and 1.040, respectively. This shows that accessibility within the apartment complexes is relatively better than the survey area. The global integration of the outside senior citizen centers was 1.224, 1.206, 1.235, 1.399, $1.234,0.998,1.154$, and 1.055, respectively. Based on the results, Senior Citizen Center F is considered to be less accessible as the global integration is lower than the survey area and inside the apartment complexes. This is because Seokchon Lake blocks the circulation or traffic line north of Senior Citizen Center F.

Third, as shown in Table 5, the maximum, minimum, and mean local integration (related to recognizability) of the survey area were $3.827,0.333$, and 1.699 , respectively. The maximum, minimum, and mean local integration inside the apartment complexes were 3.226, 0.378, and 1.587, respectively. This shows that the recognizability inside the apartment complexes is relatively lower than the survey area. The local integration of the eight senior citizen centers located outside of the apartment complexes were A:2.220, B:1.857, C:2.589, D:3.442, E:2.838, $\mathrm{F}: 1.832$, G:2.812, and $\mathrm{H}: 2.002$. These values are all higher than the mean values of the survey area and inside the apartment complexes, indicating that the outside senior citizen centers are in good locations in terms of circulation recognition.

Table 4. Analysis of integration map of the apartment complex

\begin{tabular}{|c|c|c|c|c|c|}
\hline \multicolumn{2}{|c|}{ Analysis Target } & $\operatorname{Max}$ & Min & Average & Integration Analysis Result Image \\
\hline \multicolumn{2}{|c|}{ Apartment complex } & 1.784 & 0.506 & 1.040 & \\
\hline \multicolumn{2}{|c|}{$\begin{array}{l}\text { Jamsil-dong + Samjeon-dong + } \\
\text { Seokchon-dong }\end{array}$} & 1.799 & 0.309 & 1.015 & \\
\hline \multirow{8}{*}{$\begin{array}{l}\text { Outside senior citizen } \\
\text { center }\end{array}$} & A & & & 1.224 & \\
\hline & $\mathrm{B}$ & & & 1.206 & \\
\hline & $\mathrm{C}$ & & & 1.235 & \\
\hline & $\mathrm{D}$ & & & 1.399 & \\
\hline & $\mathrm{E}$ & & & 1.234 & \\
\hline & $\mathrm{F}$ & & & 0.998 & \\
\hline & $\mathrm{G}$ & & & 1.154 & \\
\hline & $\mathrm{H}$ & & & 1.055 & \\
\hline
\end{tabular}

Table 5. Analysis of local integration map of the apartment complex

\begin{tabular}{|c|c|c|c|c|c|}
\hline \multicolumn{2}{|c|}{ Analysis Target } & $\operatorname{Max}$ & Min & Average & Local Integration Analysis Result Image \\
\hline \multicolumn{2}{|c|}{ Apartment complex } & 3.226 & 0.378 & 1.587 & \\
\hline \multicolumn{2}{|c|}{$\begin{array}{l}\text { Jamsil-dong + Samjeon-dong + } \\
\text { Seokchon-dong }\end{array}$} & 3.827 & 0.333 & 1.699 & \\
\hline \multirow{8}{*}{$\begin{array}{l}\text { Outside senior citizen } \\
\text { center }\end{array}$} & A & \multirow{8}{*}{\multicolumn{2}{|c|}{ - }} & 2.200 & \\
\hline & $\mathrm{B}$ & & & 1.857 & \\
\hline & $\mathrm{C}$ & & & 2.589 & \\
\hline & $\mathrm{D}$ & & & 3.442 & \\
\hline & $\mathrm{E}$ & & & 2.838 & \\
\hline & $\mathrm{F}$ & & & 1.832 & \\
\hline & G & & & 2.812 & \\
\hline & $\mathrm{H}$ & & & 2.002 & \\
\hline
\end{tabular}


Based on the above, the accessibility and recognizability of the apartment complexes and the outside senior citizen centers can be obtained by analyzing the hierarchy of the circulation system. Compared to the survey area (Jamsil-dong, Samjeon-dong, and Seokchon-dong), the accessibility of the four apartment complexes is good, but the recognizability is relatively low. Based on this, the outside senior citizen centers are located in areas with better accessibility and recognizability in terms of spatial hierarchy as the index values of these centers are higher than the values derived from the survey area and apartment complexes. Also, all of the apartment complexes were built after 2000, but the outside senior citizen centers opened before the year 2000. This proves that these senior citizen centers were already available for the elderly in this neighborhood even before these apartment complexes were built. Although it is mandatory by law to build senior citizen centers inside apartment complexes, the use of these facilities is distributed because of the outside senior citizen centers with good accessibility and recognizability in terms of circulation. Therefore, it is necessary to ensure sufficient internal usage by considering factors related to outside senior citizen centers when planning senior citizen centers inside apartment complexes in the future.

\section{Conclusions}

This study derived and compared the indices of senior citizen centers located inside and outside of the apartment complexes in Songpa-gu, Korea, by using space syntax. The main findings are as follows. First, this study identified the locations of areas concentrated with apartment complexes and the senior citizen centers located outside of these complexes in Songpa-gu, Korea, and derived the index representing accessibility. The results showed that the spatial hierarchy of the outside senior citizen centers was higher compared to inside the apartment complexes, indicating a relatively higher rate of utilization. Second, as a result of analyzing the local integration of the senior citizen centers, the mean values of the outside senior citizen centers were all higher than the mean values of the survey area and inside the apartment complexes, showing that the outside senior citizen centers are all located in areas with relatively better recognizability. Third, all of the outside senior citizen centers opened before 2000, and the apartment complexes were built after 2000, so the senior citizen centers were available to the elderly even before these complexes were built. Therefore, the utilization rate is expected to be high due to good accessibility and recognizability in terms of circulation. In conclusion, when planning senior citizen centers inside apartment complexes, the use of these facilities should be activated by ensuring the accessibility and recognizability of internal circulations by considering outside senior citizen centers. Moreover, these facilities should be located within the optimal range of circulation inside the complex in consideration of the elderly.

Although this study is significant because it provides basic data to establish a correlation by analyzing the spatial hierarchy of apartment complexes and outside senior citizen centers, it does not reflect physical characteristics such as the length of the axial lines in the analysis. Additional studies will be performed in the future by comparing the hierarchy analysis indices of senior citizen centers inside and outside apartment complexes and conducting usage surveys on the conclusions of this study.

\section{References}

[1] Y. S. Kon and C. H. Cho, "An exploratory study on the digital aging policies as solutions for an aging society," Journal of Digital Convergence, vol.14, no.11, pp.115-123, (2016) DOI: 10.14400/JDC.2016.14.11.115 
[2] Naver Knowledge White Paper, "An aging society," Naver Dictionary, http://terms.naver.com/entry.nhn?docId=931302\&cid=43667\&categoryId=43667

[3] Press release, "Social indicators of Korea 2017," Statistics Korea, http://kostat.go.kr/portal/korea/kor_nw/1/1/index.board?bmode=read\&aSeq=366758

[4] Korea Economic News, "The world population is 7.7 billion this year, 10.9 billion in 2100...aging," Korea Economic, https://www.hankyung.com/international/article/201906188122Y

[5] Y. K. Son and S. M. Choi, "The effects of preparation for later life on life satisfaction after retirement: Focused on gender difference," Social Work Practice Research, vol.17, no.2, pp.5-40, (2020) DOI:10.38082/SWPR.2020.17.02.5

[6] Naver Knowledge White Paper, "Senior citizen center," Naver Dictionary, https://terms.naver.com/entry.nhn?docId=566447\&cid=46634\& categoryId=46634

[7] Ministry of Land, Infrastructure, and Transport of Korea, "Regulations for housing construction standards," National Center for Legal Information of Korea, https://www.law.go.kr

[8] X. L. Zhao, S. W. Lee, and H. W. Lee, "A study on the hierarchy analysis for improving the utilization of parks in the living area: Case-based on Geumcheon-gu, Seoul, Korea,” Asia-pacific Journal of Convergent Research Interchange, vol. 6, no.12, pp.61-71, (2020) DOI: 10.47116/apjcri.2020.12.06

[9] Press release, "Total results of the 2015 census of population and housing," Statistics Korea, http://kostat.go.kr/portal/korea/kor_nw/1/1/index.board 
A Basic Study on the Spatial Hierarchy Correlation between Apartment Complexes and Senior Citizen Centers

This page is empty by intention. 